\title{
High-frequency phage-mediated gene transfer in freshwater environments determined at single-cell level
}

\author{
Takehiko Kenzaka ${ }^{1,2}$, Katsuji Tani ${ }^{1,2}$ and Masao $\mathrm{Nasu}^{2}$ \\ ${ }^{1}$ Environmental Science and Microbiology, Faculty of Pharmacy, Osaka Ohtani University, Nishikiori-kita, \\ Tondabayashi, Japan and ${ }^{2}$ Environmental Science and Microbiology, Graduate School of Pharmaceutical \\ Sciences, Osaka University, Yamada-oka, Suita, Japan
}

\begin{abstract}
Lateral gene transfer by phages has contributed significantly to the genetic diversity of bacteria. To accurately determine the frequency and range of phage-mediated gene transfer, it is important to understand the movement of DNA among microbes. Using an in situ DNA amplification technique (cycling primed in situ amplification-fluorescent in situ hybridization; CPRINS-FISH), we examined the propensity for phage-mediated gene transfer in freshwater environments at the single-cell level. Phage P1, T4 and isolated Escherichia coli phage EC10 were used as vectors. All E. coli phages mediated gene transfer from $E$. coli to both plaque-forming and non-plaque-forming Enterobacteriaceae strains at frequencies of $0.3-8 \times 10^{-3}$ per plaque-forming unit (PFU), whereas culture methods using selective agar media could not detect transductants in non-plaque-forming strains. The DNA transfer frequencies through phage EC10 ranged from undetectable to $9 \times 10^{-2}$ per PFU (undetectable to $2 \times 10^{-3}$ per total direct count) when natural bacterial communities were recipients. Direct viable counting combined with CPRINS-FISH revealed that more than $20 \%$ of the cells carrying the transferred gene retained their viability in most cases. These results indicate that the exchange of DNA sequences among bacteria occurs frequently and in a wide range of bacteria, and may promote rapid evolution of the prokaryotic genome in freshwater environments.

The ISME Journal (2010) 4, 648-659; doi:10.1038/ismej.2009.145; published online 21 January 2010

Subject Category: evolutionary genetics

Keywords: bacteriophage; freshwater; lateral gene transfer; transduction
\end{abstract}

\section{Introduction}

Bacteriophages are abundant and ubiquitous in the natural environment. They induce bacterial mortality, contribute to the carbon cycle and also affect host diversity (Fuhrman, 1999). Moreover, they mediate gene transfer between prokaryotes. Recent whole-genome analyses suggest that lateral gene transfer by phages has contributed significantly to the acquisition of new genetic traits, the ability of bacteria to exploit new environments and the genetic diversity of many bacteria (Ochman et al., 2000; Brüssow et al., 2004; Bordenstein and Reznikoff, 2005; Pallen and Wren, 2007). In gene transfer by phages, phage particles accidentally incorporate a piece of the bacterial DNA into a phage head in place of phage DNA during the propagation. As phage capsids prevent nuclease

Correspondence: K Tani, Environmental Science and Microbiology, Faculty of Pharmacy, Osaka Ohtani University, 3-11-1, Nishikiori-kita, Tondabayashi, 584-8540, Japan.

E-mail: tanika@osaka-ohtani.ac.jp

Received 28 July 2009; revised 19 November 2009; accepted 22 November 2009; published online 21 January 2010 digestion, phages may serve as reservoirs for foreign genes. Potential gene transfer via phages has been documented in soil, freshwater and marine water environments (Saye et al., 1987; Zeph et al., 1988; Jiang and Paul, 1998). In these studies, researchers inoculated well-known or isolated phages packed with indicator genes into environmental samples and performed transduction assays using natural bacterial communities as recipients. They have suggested that transduction could be an important mechanism for lateral gene transfer in natural environments.

Culture methods using selective agar media have a leading role in the study of transduction (Zinder and Lederberg, 1952; Ogunseitan, 2008). However, many environmental bacteria are resistant to culture on conventional media (Amann et al., 1995). In addition, the genetic characteristics used as an indicator for transduction are found in indigenous bacteria. For instance, there are antibiotic-resistant bacteria in the natural environment; their occurrence makes it difficult to distinguish indigenous antibioticresistant bacteria from transductants (Teuber, 2001). Transfer of foreign DNA molecules (DNA entry) into a recipient bacterium is an important first step in genetic diversification through lateral gene transfer, 
but the expression level of the transferred gene and cell growth on media may differ for each recipient cell. Culture methods have a limited ability to quantify the genetic material introduced into individual cells at the DNA level. Thus, our current knowledge of gene transfer via phages in the environment is rather limited because of such methodological constraints.

Detection of single-copy genes in individual cells is necessary to determine the frequency and range of DNA transfer in environmental bacteria, and to understand gene flow among microorganisms. In situ DNA amplification methods allow the visualization of specific DNA sequences inside bacterial cells (Kenzaka et al., 2005; Maruyama et al., 2005), clarifying the movement of a specific gene among Escherichia coli cells at the single-cell level (Kenzaka et al., 2007). The purpose of this study was to investigate the propensity for DNA transfer via phages in natural freshwater habitats at the singlecell level. We used an in situ DNA amplification technique (cycling primed in situ amplificationfluorescent in situ hybridization; CPRINS-FISH; Kenzaka et al., 2005), and both frequency and possible range of DNA transfer via three $E$. coli phages ( $\mathrm{P} 1, \mathrm{~T} 4$ and isolated phage) were first examined at the single-cell level using both plaqueforming and non-plaque-forming Enterobacteriaceae strains as recipients. To explore the viability of cells that acquired the gene from phage, direct viable counting (DVC) was carried out after DNA was transferred by phages (Kogure et al., 1979). The propensity of DNA transfer obtained by this method was compared with values determined by conventional methods. Green fluorescent protein gene $(g f p)$ was used as an indicator of gene transfer because the freshwater samples used in this study did not contain the $g f p$ gene sequence.

\section{Materials and methods}

Bacterial strains

Bacterial strains used in this study are described as follows: Citrobacter freundii IFO 12681, Enterobacter aerogenes BM 2688, E. coli C600 RK2, E. coli NBRC 12713 KEN1, which carries transposon Tn1 (4951 bp) including an ampicillin resistance gene (beta lactamase gene; bla) on the chromosome, E. coli NBRC 12713 with or without RK2::gfp, E. coli W3110 with or without plasmid RK2::gfp, Pseudomonas putida ATCC 12633, Proteus mirabilis clinical isolate, Salmonella enteritidis IID 640, Serratia marcescens clinical isolate, Yersinia enterocolitica IID 981. The gfp-tagged broad host-range plasmid RK2 (RK2::gfp) was constructed using RK2 and pGFPuv (Clontech Laboratories, Palo Alto, CA, USA) as described by Jorquera et al. (2006). E. coli strains were grown in Luria-Bertain (LB) medium (1\% tryptone, $0.5 \%$ yeast extract, $0.5 \% \mathrm{NaCl}$ ) at $37^{\circ} \mathrm{C}$. Strains with the bla gene were cultured in LB broth containing
$50 \mu \mathrm{g} \mathrm{ml}^{-1}$ ampicillin. Other strains were grown in LB medium at $30^{\circ} \mathrm{C}$. The absence of bla gene and $g f p$ gene in the genomic DNA of all recipient strains was confirmed by PCR targeting the genes before transduction and DNA transfer experiments were performed.

\section{Bacteriophage}

Phage P1kc NBRC 20008, a derivative of phage P1 was obtained from National Institute of Technology and Evaluation, Japan (Enomoto and Stocker, 1974). Phage T4GT7, a derivative of phage T4 was obtained from National Institute of Genetics, Japan (Wilson et al., 1979). Transducing E. coli phage EC10 was isolated from eutrophic river (Kenzaka et al., 2007). Phages were propagated with appropriate donor $E$. coli strains (NBRC 12713 KEN1 for P1 $k c$ and T4GT7, E. coli W3110 RK2::gfp or E. coli NBRC 12713 RK2::gfp for EC10) in 11 LB broth containing $0.2 \% \mathrm{MgSO}_{4}$ and $10 \mathrm{mM} \mathrm{CaCl}{ }_{2}$ overnight at $37^{\circ} \mathrm{C}$. Purification of phages by ultracentrifugation was performed as described by Kenzaka et al. (2007). DNase treatment was performed before phages were purified by ultracentrifugation to prevent transformation. Before transduction and DNA transfer experiments, DNA was extracted from each phage (P1, T4 and EC10) infecting E. coli strains lacking the bla and gfp genes using the Wizard Lambda Preps DNA Purification System (Promega, Madison, WI, USA), and the absence of the bla and $g f p$ genes was confirmed by PCR.

\section{Environmental samples}

Surface river water samples were taken from Kitahashi in the Neyagawa River, Juhachijo in the Kanzakigawa River, Kuwazu in the Inagawa River and Takiue in the Minohgawa River, in the northern part of Osaka, Japan (Figure 1). At the sites, water samples were collected twice in early spring of 2005 (February-March) and three times in autumn of 2009 (October-November). Kitahashi is located in a commercial area, Osaka Business Park. Kuwazu is located in an industrial area. These sites were considered to be polluted by organic carbon (Tani et al., 1996; Yamaguchi and Nasu, 1997; Kenzaka et al., 2001). Takiue is surrounded by forest and is an oligotrophic site. At the site, the river is narrow and shallow, and the water is not exposed to domestic or industrial effluents (Tani et al., 1996; Kenzaka et al., 1998, 2001). The water samples were collected in sterile 500-ml glass bottles and carried to the laboratory on ice. The absence of $g f p$ gene in environmental samples was confirmed by PCR before DNA transfer experiments were performed.

\section{Plaque assays}

A volume of $100 \mu \mathrm{l}$ of stationary-phase cultures of bacterial strains was incubated with $10 \mu$ of diluted phage $\left(10^{-1}-10^{-12}\right)$ in $90 \mu \mathrm{l}$ of SM buffer $\left(50 \mathrm{mmol}^{-1}\right.$ 


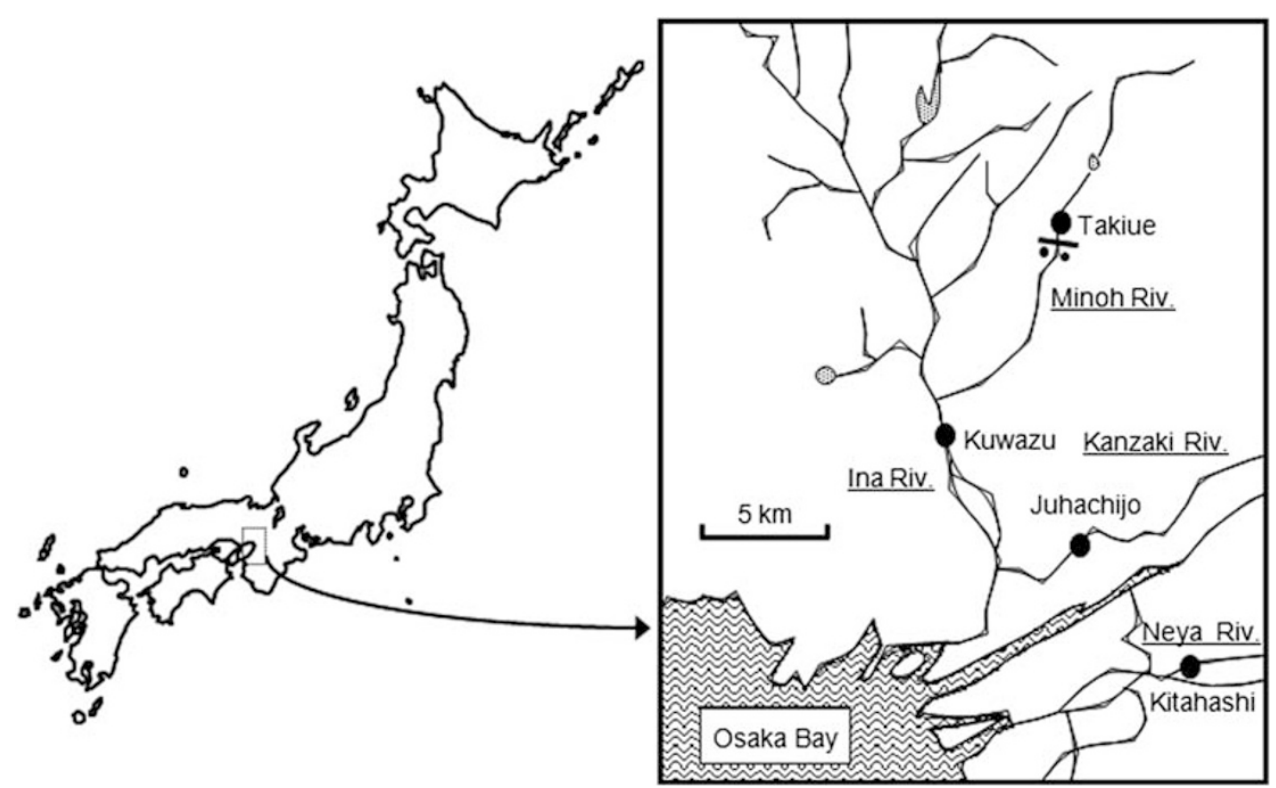

Figure 1 Map of river water sampling point. The sampling sites are marked by black circles. Takiue is located upstream of the Minoh River. Kuwazu, Juhachijo and Kitahashi are located downstream of the Ina River, the Kanzaki River and the Neya River, respectively. These rivers flow into Osaka Bay.

Tris-HCl (pH7.5), $100 \mathrm{mmol}^{-1} \mathrm{NaCl}, 8 \mathrm{mmol} \mathrm{l}^{-1}$ $\mathrm{MgSO}_{4}$ and $0.01 \%$ gelatin) at $30{ }^{\circ} \mathrm{C}$ for $10 \mathrm{~min}$. After incubation, samples were poured with LB soft agar $\left(0.8 \%\right.$ agar) on $\mathrm{LB}$ plate and incubated at $30^{\circ} \mathrm{C}$ overnight to determine the plaque formation.

\section{Transduction assays}

For cultured recipients, $200 \mathrm{ml}$ of stationary-phase cultures were collected by centrifugation at $8000 \mathrm{~g}$ for $10 \mathrm{~min}$ at $4{ }^{\circ} \mathrm{C}$ and suspended in $10 \mathrm{ml}$ of $\mathrm{LB}$ broth. A volume of $3 \mathrm{ml}$ of the suspended cultures was incubated with phages in $3 \mathrm{ml}$ of SM buffer at $37^{\circ} \mathrm{C}$ for $10 \mathrm{~min}$ at multiplicities of infection ranging from 0.2 to 2. Each control contained an equal volume of the recipient cell culture and SM buffer. After a 10 -min adsorption period at $37^{\circ} \mathrm{C}$ for E. coli and at $30^{\circ} \mathrm{C}$ for other strains, cells were placed onto selective LB plates containing $50 \mu \mathrm{g} \mathrm{ml}^{-1}$ ampicillin and incubated at $30^{\circ} \mathrm{C}$ for 2 days. The transducing phage lysate (containing no recipient) and recipient (containing no transducing phage) were also plated onto selective plates as a control. The frequencies of transduction were represented as the number of colonies on the selective LB plates per initial number of colonies on the non-selective LB plates (colony-forming unit; CFU) of recipient or per initial plaque-forming unit (PFU) of phage. Results presented are averages of three transduction experiments.

\section{DNA transfer experiments}

A volume of $200 \mu \mathrm{l}$ of stationary-phase culture was incubated with $200 \mu \mathrm{l}$ of SM buffer containing each phage at $37^{\circ} \mathrm{C}$ for $10 \mathrm{~min}$ at multiplicities of infection ranging from 0.2 to 2 . The concentration of bacterial cells was adjusted to approximately $1 \times 10^{9}$ cells per ml. For other strains used as recipients, cultures were incubated with phages at $30^{\circ} \mathrm{C}$ for $10 \mathrm{~min}$. For gene transfer assays with recipients at low concentration, concentration of E. coli was adjusted to approximately $1 \times 10^{5}, 10^{6}$, $10^{7}$ and $10^{8}$ cells per $\mathrm{ml}$, and $1 \%$ of E. coli was added to $P$. putida at the concentration ranging from $4 \times 10^{5}$ to $10^{7}$ cells per $\mathrm{ml}$. The diluted cultures were incubated with phage EC10 at $25^{\circ} \mathrm{C}$ for $10 \mathrm{~min}$ at the multiplicity of infection 2. For gene transfer experiments in which indigenous river bacterial communities were used as recipients, 10-100-ml portions of river water samples were incubated with phage EC10 at $25{ }^{\circ} \mathrm{C}$ for $20 \mathrm{~min}$ at mixing ratio ranging from 2 to 200 . The mixing ratio was calculated on the basis of the number of bacteria stained by SYBR Gold-labeled phage EC10 in river water samples as described below.

After the mixtures of recipients and phage were incubated under the conditions, as mentioned above, samples were fixed with $4 \%$ paraformaldehyde in phosphate-buffered saline $\left(0.13 \mathrm{~mol} \mathrm{l}^{-1}\right.$ $\mathrm{NaCl}, 7 \mathrm{mmol} \mathrm{l}^{-1} \mathrm{Na}_{2} \mathrm{HPO}_{4}$ and $3 \mathrm{mmol} \mathrm{l}^{-1} \mathrm{NaH}_{2} \mathrm{PO}_{4}$ (pH 7.2)) at $4{ }^{\circ} \mathrm{C}$ for $16 \mathrm{~h}$. After fixation, $1 \mu \mathrm{l}-30-\mathrm{ml}$ portions were filtered through gelatin $(0.1 \%$ gelatin, $\left.0.01 \% \mathrm{CrK}\left(\mathrm{SO}_{4}\right)_{2}\right)$-coated polycarbonate white filters $(0.2 \mu \mathrm{m}$ pore size, $25 \mathrm{~mm}$ diameter, ADVANTEC, Tokyo, Japan) and rinsed twice with filtered deionized water. Then samples were stored at $-20{ }^{\circ} \mathrm{C}$.

Viability of recipient cells determined by DVC

To explore the viability of the recipient cells carrying the transferred gene, DVC was carried out. 
After recipient cell culture was mixed with each phage under the conditions, as mentioned above, $20 \mu \mathrm{l}$ of the mixture was added to $180 \mu \mathrm{l}$ of LB broth containing an antibiotic cocktail (final concentration: $20 \mu \mathrm{g} \mathrm{ml}^{-1}$ nalidixic acid, $10 \mu \mathrm{g} \mathrm{ml}^{-1}$ piromidic acid, $10 \mu \mathrm{g} \mathrm{ml}^{-1}$ pipemidic acid, $10 \mu \mathrm{g} \mathrm{ml}^{-1}$ cephaloxin and $0.1 \mu \mathrm{g} \mathrm{ml}^{-1}$ ciprofloxacin; Joux and Lebaron, 1997) and incubated at $37^{\circ} \mathrm{C}$ for E. coli or $30^{\circ} \mathrm{C}$ for other bacteria for $3 \mathrm{~h}$. For river water samples, after the samples were mixed with the phage EC10 under conditions mentioned above, antibiotic cocktail was added to the mixture at the above final concentrations, and incubated at $25^{\circ} \mathrm{C}$ for $18 \mathrm{~h}(30 \mathrm{~h}$ for sample from oligotrophic site, Takiue).

After incubation for DVC, samples were fixed with $4 \%$ paraformaldehyde in phosphate-buffered saline at $4{ }^{\circ} \mathrm{C}$ for $16 \mathrm{~h}$. After fixation, samples were filtered and were stored at $-20^{\circ} \mathrm{C}$ as described above.

\section{Oligonucleotides and polynucleotides}

Oligonucleotide primers and polynucleotide probes for CPRINS-FISH used in this study were described as follows. AmpR840r primer and three probes for the bla gene were reported in the study by Kenzaka et al. (2005). The nucleotide sequences of $g f p$ gene were obtained from GenBank (Release 138.0), and gfp717r primer ( $5^{\prime}$-TTATTTGTAGAGCTCATCCA-3') and probes $\left(5^{\prime}\right.$-GATGGTGATGTTAATGGGCACAAA TTTTCTGTCAGTGGAGAGGGTGAAGG-3'; $5^{\prime}$-GAC TTTTTCAAGAGTGCCATGCCCGAAGGTTATGTAC AGGAACGC- $3^{\prime} ; 5^{\prime}$-GATGACGGGAACTACAAGACG CGTGCTGAAGTCAAGTTTGAAGG-3'; $5^{\prime}$-ATTGGC GATGGCCCTGTCCTTTTACCAGACAACCATTACC TGTCCA-3' ${ }^{\prime}$; $5^{\prime}$-CGAAAGATCCCAACGAAAAGCGT GACCACATGGTCCTTCTTGAG-3') for the $g f p$ gene were designed in this study. The specificities of the primer and probe sequences were verified against National Center for Biotechnology Information nucleotide databases using the Basic Local Alignment Search Tool program (Altschul et al., 1997). All primers and polynucleotide probes were purchased from Texas Genomics (Tokyo, Japan), and probes were labeled with Alexa Fluor 546 at guanine using ULYSIS Alexa Fluor 546 Nucleic Acid Labeling Kit (Invitrogen, Tokyo, Japan) and the manufacturer's recommended procedures.

\section{CPRINS-FISH}

To detect cells carrying the bla or gfp gene transferred by phage, CPRINS-FISH was performed. Permeabilization for CPRINS-FISH was carried out as described in the study by Kenzaka et al. (2005). Filters with bacterial cells were coated in gelatin to avoid cell loss during extensive cell wall permeabilization. After lysozyme treatment, each filter was cut into 16 sections and subjected to CPRINS-FISH.

A one-sixteenth section of the filter was transferred to a microtube (volume: $0.2 \mathrm{ml}$ ) and immersed in $100 \mu \mathrm{l}$ of the CPRINS buffer (Kenzaka et al., 2007).
Cycling primed in situ amplification cycles consisted of a hot start at $95{ }^{\circ} \mathrm{C}$ for $9 \mathrm{~min}$, denaturation at $94{ }^{\circ} \mathrm{C}$ for $1 \mathrm{~min}$, annealing at $62^{\circ} \mathrm{C}$ for $30 \mathrm{~s}$ and $72{ }^{\circ} \mathrm{C}$ for 1.5-min extension for AmpR840r primer or annealing at $58{ }^{\circ} \mathrm{C}$ for $30 \mathrm{~s}$ and $72{ }^{\circ} \mathrm{C}$ for 2 -min extension for gfp717r primer. Amplification was repeated for 30 cycles with a thermal cycler (PTC-200, Bio-Rad Laboratories, Hercules, CA, USA). After amplification, filters were rinsed with $0.1 \%$ Nonidet P40 and sterile deionized water, dehydrated in $99 \%$ ethanol and vacuum dried. Hybridization, washing and 4',6-diamidino-2-phenylindole (DAPI) staining were performed as described in the study by Kenzaka et al. (2007). To exclude the possibility of nonspecific probe binding to cell structures other than target DNA in the target cells, (i) FISH using laboratory strains and environmental samples without amplification of target DNA, (ii) CPRINS-FISH targeting the bla or $g f p$ gene using E. coli strains that did not carry the genes, and (iii) CPRINS-FISH targeting chloramphenicol acetyltransferase gene using laboratory strains that did not carry the chloramphenicol acetyltransferase gene (Kenzaka et al., 2005), were performed.

\section{Epifluorescence microscopy}

Filters were observed under an epifluorescence microscope (E-400; Nikon, Tokyo, Japan) with the Nikon filter sets UV-2A (EX300-350, DM400 and BA420) for DAPI, B-2A (EX450/490, DM505 and BA520) for SYBR Gold and HQ-CY3 (G535/50, FT565 and BP610/75) for Alexa Fluor 546, respectively. Images were acquired by a cooled charge-coupled device camera (Cool Snap; Roper Photometrics, Tuscon, AZ, USA) and stored as digital files. Exposure time was $0.1 \mathrm{~s}$ for DAPI, $0.5 \mathrm{~s}$ for SYBR Gold and $1 \mathrm{~s}$ for Alexa Fluor 546, respectively. A total of 3000-30000 DAPI-stained objects were counted per sample. Frequencies of gene transfer determined by CPRINS-FISH were represented as the number of CPRINS-FISH-positive cells per initial total direct counts (TDCs) of recipient or per initial PFU of phage. Frequencies were determined in triplicate for each sample. Differences between means of frequencies were tested by the Student's $t$-test with Microsoft Excel XP software (Microsoft, Redmond, WA, USA).

\section{Fluorescent bacteriophage assays}

Fluorescently stained bacteriophages were produced by using a modification of procedure described by Maniatis et al. (1982). The phage, EC10, was propagated with E. coli C600 RK2 in $250 \mathrm{ml} \mathrm{LB}$ broth containing $0.2 \% \mathrm{MgSO}_{4}$ overnight at $37^{\circ} \mathrm{C}$. The cell culture was centrifuged at $8000 \mathrm{~g}$, $10 \mathrm{~min}, 4^{\circ} \mathrm{C}$, and the supernatant was withdrawn. After nuclease treatment with DNase and RNase at $37^{\circ} \mathrm{C}$ for $1 \mathrm{~h}, \quad 0.2 \mu \mathrm{ml}^{-1}$ SYBR Gold $(10000 \times$, Invitrogen) was added and stained at $37^{\circ} \mathrm{C}$ for $1 \mathrm{~h}$. 
The stained sample was subjected to polyethylene glycol precipitation. Stained phage particles were further purified by ultracentrifugation.

A volume of $10 \mu \mathrm{l}$ of both log-phase and stationaryphase cultures were incubated with $10 \mu \mathrm{l}$ of the purified SYBR Gold-labeled phage at $37^{\circ} \mathrm{C}$ for $20 \mathrm{~min}$. For estimating the bacterial population to which phage EC10 could inject their DNA in river water samples, $1 \mathrm{ml}$ of water samples were mixed with $20 \mu \mathrm{l}$ of the SYBR Gold-labeled phage at $30^{\circ} \mathrm{C}$ for $20 \mathrm{~min}$. After incubation, samples were fixed in $4 \%$ paraformaldehyde in phosphate-buffered saline at room temperature (ca. $20^{\circ} \mathrm{C}$ ) for $10 \mathrm{~min}$. After fixation, samples were stained with $1 \mu \mathrm{g} \mathrm{ml}^{-1}$ DAPI for $5 \mathrm{~min}$, and filtered through a polycarbonate filter (pore size: $0.2 \mu \mathrm{m}$; ADVANTEC). Filters were mounted in immersion oil for observation by epifluorescence microscopy.

\section{Results}

Gene transfer via phage $P 1$ and T4

Phage P1 and T4GT7 are commonly used, generalized transducing phages for E. coli. They have the ability to mediate gene transfer from $E$. coli to not only E. coli but to also some plaque-forming Enterobacteriaceae strains (Goldberg et al., 1974; Tetart et al., 1996). The frequency and possible range of transfer of the bla gene on the NBRC 12713 KEN1 chromosome of E. coli via the two phages was first examined by both a culture-based method using selective medium containing ampicillin and a culture-independent method with CPRINS-FISH targeting the bla gene. Plaque-forming strains and non-forming Enterobacteriaceae strains were used as recipients.
Transduction was observed in E. aerogenes and E. coli, which were plaque-forming strains, and the transduction frequencies for the bla gene on selective medium were $0.6-2 \times 10^{-6}$ transductants per PFU for P1 $k c$ (Table 1), and undetectable to $2 \times 10^{-8}$ transductants per PFU for T4GT7 (Table 2) at a multiplicity of infection 1. Although non-plaqueforming strains did not have the bla gene, they could grow on selective medium containing ampicillin perhaps due to overproduction of multidrug-resistant efflux pump when they were plated at high density (ca. $>10^{7}$ CFUs per ml). Thus it was hard to determine the transduction frequency in the nonplaque-forming strains by conventional methods.

The frequencies of DNA transfer determined by CPRINS-FISH were $3-8 \times 10^{-3}$ per PFU for P1 kc (Table 1) and $0.3-2 \times 10^{-3}$ per PFU for T4GT7 (Table 2) in plaque-forming strains. The CPRINSFISH analysis revealed that both P1 $k c$ and T4GT7 transferred the bla gene to non-plaque-forming strains. Phage $\mathrm{P} 1 k_{c}$ transferred the bla gene to C. freundii and $S$. enteritidis at similar frequencies $\left(0.8-4 \times 10^{-3}\right.$ per PFU), and phage T4GT7 transferred the bla gene to $C$. freundii, $P$. mirabilis, $S$. enteritidis and $Y$. enterocolitica at similar frequencies $\left(0.5-2 \times 10^{-3}\right.$ per PFU).

Viable bacteria carrying transferred genes may be infected by other phages and the transferred gene could be further transferred to other bacteria. They may also maintain the transferred gene. Thus, DVC and CPRINS-FISH were combined to estimate viable cells carrying the transferred bla gene. Representative photographs of viable $C$. freundii cells to which the bla gene was transferred by phage P1 kc are shown in Figures 2a and b. Direct viable counting combined with CPRINS-FISH visualized the target viable recipients as elongated cells that

Table 1 Infection range of phage P1kc and DNA transfer frequencies of bla gene with Enterobacteriaceae strains as recipient ${ }^{\mathrm{a}}$

\begin{tabular}{|c|c|c|c|c|c|c|c|}
\hline \multirow[t]{3}{*}{ Recipient } & \multirow[t]{3}{*}{ Plaque $^{\mathrm{b}}$} & \multicolumn{2}{|c|}{$\begin{array}{l}\text { Transductant frequency } \\
\text { per indicated unit }{ }^{\mathrm{c}}\end{array}$} & \multicolumn{4}{|c|}{$\begin{array}{l}\text { DNA transfer frequency per indicated unit as } \\
\text { determined by indicated method }\end{array}$} \\
\hline & & \multirow[t]{2}{*}{ Per $C F U$} & \multirow[t]{2}{*}{ Per PFU } & \multicolumn{2}{|c|}{ CPRINS $^{\mathrm{d}}$} & \multicolumn{2}{|c|}{$D V C-C P R I N S^{\mathrm{e}}$} \\
\hline & & & & Per TDC & Per PFU & Per TDC & Per PFU \\
\hline C. freundii & - & $N D^{f}$ & ND & $(4 \pm 1) \times 10^{-3}$ & $(4 \pm 1) \times 10^{-3}$ & $(4 \pm 2) \times 10^{-3}$ & $(4 \pm 2) \times 10^{-3}$ \\
\hline E. aerogenes & + & $(6 \pm 0.5) \times 10^{-7}$ & $(6 \pm 0.5) \times 10^{-7}$ & $(8 \pm 2) \times 10^{-3}$ & $(8 \pm 2) \times 10^{-3}$ & $(4 \pm 2) \times 10^{-3}$ & $(4 \pm 2) \times 10^{-3}$ \\
\hline E. coli & + & $(2 \pm 0.5) \times 10^{-6}$ & $(2 \pm 0.5) \times 10^{-6}$ & $(3 \pm 1) \times 10^{-3}$ & $(3 \pm 1) \times 10^{-3}$ & $(2 \pm 0.8) \times 10^{-3}$ & $(2 \pm 0.8) \times 10^{-3}$ \\
\hline P. mirabilis & - & ND & ND & $<1 \times 10^{-4}$ & $<1 \times 10^{-4}$ & $<7 \times 10^{-5}$ & $<7 \times 10^{-5}$ \\
\hline S. enteritidis & - & ND & ND & $(8 \pm 3) \times 10^{-4}$ & $(8 \pm 3) \times 10^{-4}$ & $(1 \pm 0.3) \times 10^{-3}$ & $(1 \pm 0.3) \times 10^{-3}$ \\
\hline Y. enterocolitica & - & ND & ND & $<1 \times 10^{-4}$ & $<1 \times 10^{-4}$ & $<1 \times 10^{-5}$ & $<1 \times 10^{-5}$ \\
\hline
\end{tabular}

Abbreviations: CFU, colony-forming unit; CPRINS-FISH, cycling primed in situ amplification-fluorescent in situ hybridization; DVC, direct viable count; LB, Luria-Bertain medium; MOI, multiplicity of infection; ND, not detectable; PFU, plaque-forming unit; TDC, total direct count.

${ }^{a}$ Frequencies are shown per CFU, PFU or TDC. Values indicate means \pm s.d. values for triplicate samples.

'Infection range was determined by plaque assay. +, positive; - , negative.

cTransductants were incubated on LB agar medium containing ampicillin for 2 days.

${ }^{\mathrm{d}}$ Frequencies were determined by CPRINS-FISH at MOI of 1.

eViable cells carrying gfp gene were detected by combined DVC and CPRINS-FISH.

${ }^{\mathrm{f}} \mathrm{ND}$, not detectable. When plating recipient cells at high cell density ( $>10^{7}$ CFUs per ml), they could grow on LB agar medium containing ampicillin. Thus, it was hard to detect transductant. 
Table 2 Infection range of phage T4GT7 and DNA-transfer frequencies of bla gene with Enterobacteriaceae strains as recipient ${ }^{\mathrm{a}}$

\begin{tabular}{|c|c|c|c|c|c|c|c|}
\hline \multirow[t]{3}{*}{ Recipient } & \multirow[t]{3}{*}{ Plaque } & \multicolumn{2}{|c|}{$\begin{array}{l}\text { Transductant frequency } \\
\quad \text { per indicated unit }\end{array}$} & \multicolumn{4}{|c|}{$\begin{array}{l}\text { DN- transfer frequency per indicated unit as } \\
\text { determined by indicated method }\end{array}$} \\
\hline & & \multirow[t]{2}{*}{ Per CFU } & \multirow[t]{2}{*}{ Per PFU } & \multicolumn{2}{|c|}{ CPRINS $^{\mathrm{d}}$} & \multicolumn{2}{|c|}{$D V C-C P R I N S^{\mathrm{e}}$} \\
\hline & & & & Per TDC & Per PFU & Per TDC & Per PFU \\
\hline C. freundii & - & $\mathrm{ND}^{\mathrm{f}}$ & ND & $(2 \pm 0.7) \times 10^{-3}$ & $(2 \pm 0.7) \times 10^{-3}$ & $(1 \pm 0.2) \times 10^{-3}$ & $(1 \pm 0.2) \times 10^{-3}$ \\
\hline E. aerogenes & + & $<2 \times 10^{-9}$ & $<2 \times 10^{-9}$ & $(3 \pm 4) \times 10^{-4}$ & $(3 \pm 4) \times 10^{-4}$ & $(1 \pm 0.5) \times 10^{-3}$ & $(1 \pm 0.5) \times 10^{-3}$ \\
\hline E. coli & + & $(2 \pm 0) \times 10^{-8}$ & $(2 \pm 0) \times 10^{-8}$ & $(2 \pm 0.8) \times 10^{-3}$ & $(2 \pm 0.8) \times 10^{-3}$ & $(6 \pm 5) \times 10^{-4}$ & $(6 \pm 5) \times 10^{-4}$ \\
\hline P. mirabilis & - & ND & ND & $(5 \pm 1) \times 10^{-4}$ & $(5 \pm 1) \times 10^{-4}$ & $(1 \pm 1) \times 10^{-3}$ & $(1 \pm 1) \times 10^{-3}$ \\
\hline S. enteritidis & - & ND & ND & $(5 \pm 4) \times 10^{-4}$ & $(5 \pm 4) \times 10^{-4}$ & $(8 \pm 2) \times 10^{-4}$ & $(8 \pm 2) \times 10^{-4}$ \\
\hline Y. enterocolitica & - & ND & ND & $(2 \pm 0.2) \times 10^{-3}$ & $(2 \pm 0.2) \times 10^{-3}$ & $(2 \pm 0.8) \times 10^{-3}$ & $(2 \pm 0.8) \times 10^{-3}$ \\
\hline
\end{tabular}

Abbreviations: CFU, colony-forming unit; CPRINS-FISH, cycling primed in situ amplification-fluorescent in situ hybridization; DVC, direct viable count; LB, Luria-Bertain medium; MOI, multiplicity of infection; ND, not detectable; PFU, plaque-forming unit; TDC, total direct count.

${ }^{a}$ Frequencies are shown per CFU, PFU or TDC. Values indicate means \pm s.d. values for triplicate samples.

'Infection range was determined by plaque assay. +, positive; -, negative.

'Transductants were incubated on LB agar medium containing ampicillin for 2 days.

${ }^{\mathrm{d}}$ Frequencies were determined by CPRINS-FISH at MOI of 1.

eViable cells carrying gfp gene were detected by combined DVC and CPRINS-FISH.

${ }_{\mathrm{f}}^{\mathrm{N} D}$, not detectable. When plating recipient cells at high cell density ( $>10^{7}$ CFUs per ml), they could grow on LB agar medium containing ampicillin. Thus, it was hard to detect transductant.

showed bright Alexa Fluor 546 fluorescence under green excitation (Figure 2b). More than $30 \%$ of the remaining cells carrying the bla gene became elongated and/or fattened, that is, possessed protein synthesis activity. The transfer frequencies determined by DVC combined with CPRINS-FISH were at least three (P1kc) or five (T4GT7) orders of magnitude higher than for colony-forming bacteria on selective medium in plaque-forming strains. Our results show that DNA transfer mediated by phage P1kc and T4GT7 happened in more divergent strains than those estimated by conventional methods.

\section{Gene transfer via isolated phage EC10}

To examine the potential for gene transfer by phages in a freshwater environment, we prepared isolated transducing phage EC10 packed with the gfp gene, and DNA transfer experiments were performed using the $g f p$ gene as an indicator of gene transfer. Phage EC10 that was propagated with E. coli NBRC 12713 RK2::gfp was mixed with Enterobacteriaceae strains.

Transfer of the bla and gfp gene on the plasmid RK2::gfp via phage EC10 was examined by both selective agar plating and CPRINS-FISH targeting the bla and gfp genes (Table 3). Frequencies on selective media containing ampicillin were undetectable in this study using E. coli NBRC 12713 RK2::gfp as a donor, although phage EC10 has the ability to transfer E. coli genes to both plasmids and chromosomes (Kenzaka et al., 2007). Frequencies of DNA transfer determined by CPRINS-FISH targeting the bla gene were $7-10 \times 10^{-3}$ per PFU. Frequencies of DNA transfer of the $g f p$ gene were slightly lower than those of the bla gene $(P<0.05)$. Most gene- positive cells determined by CPRINS-FISH retained protein synthesis activity.

Next, the possible range of transfer of the $g f p$ gene via EC10 was investigated using other Enterobacteriaceae strains as recipients (Table 4). Frequencies of DNA transfer determined by CPRINS-FISH targeting the $g f p$ gene in the strains ranged from 3 to $4 \times 10^{-3}$ per PFU. Viable cells carrying the transferred gfp gene determined by DVC combined with CPRINS-FISH constituted more than $30 \%$ of the gfp gene-positive cells determined by CPRINS-FISH. These frequencies were similar to plaque-forming E. coli (Table 3). The results demonstrated that isolated phage EC10 also has the ability to transfer the gene from E. coli to other Enterobacteriaceae strains, and conventional methods underestimate the range of phage-mediated gene transfer.

\section{Frequency of DNA transfer at low bacterial concentrations}

In natural aquatic environments, bacterial concentration is significantly lower than in laboratory conditions. Thus, DNA-transfer frequencies at low bacterial concentration were examined by CPRINSFISH (Table 5). Although it was expected that phage absorption by recipients was reduced by the low bacterial concentration, DNA-transfer frequencies were similar at a concentration of $10^{5}-10^{8} \mathrm{E}$. coli cells per ml. Usually bacterial communities in aquatic environments consist of a small number of hosts and a large number of non-hosts. As phage EC10 did not transfer the gfp gene into $P$. putida, $E$. coli was added to $P$. putida and DNA transfer experiments were performed to examine the effect of a small population size on DNA-transfer frequency. The CPRINS-FISH analysis on a polycarbonate filter 

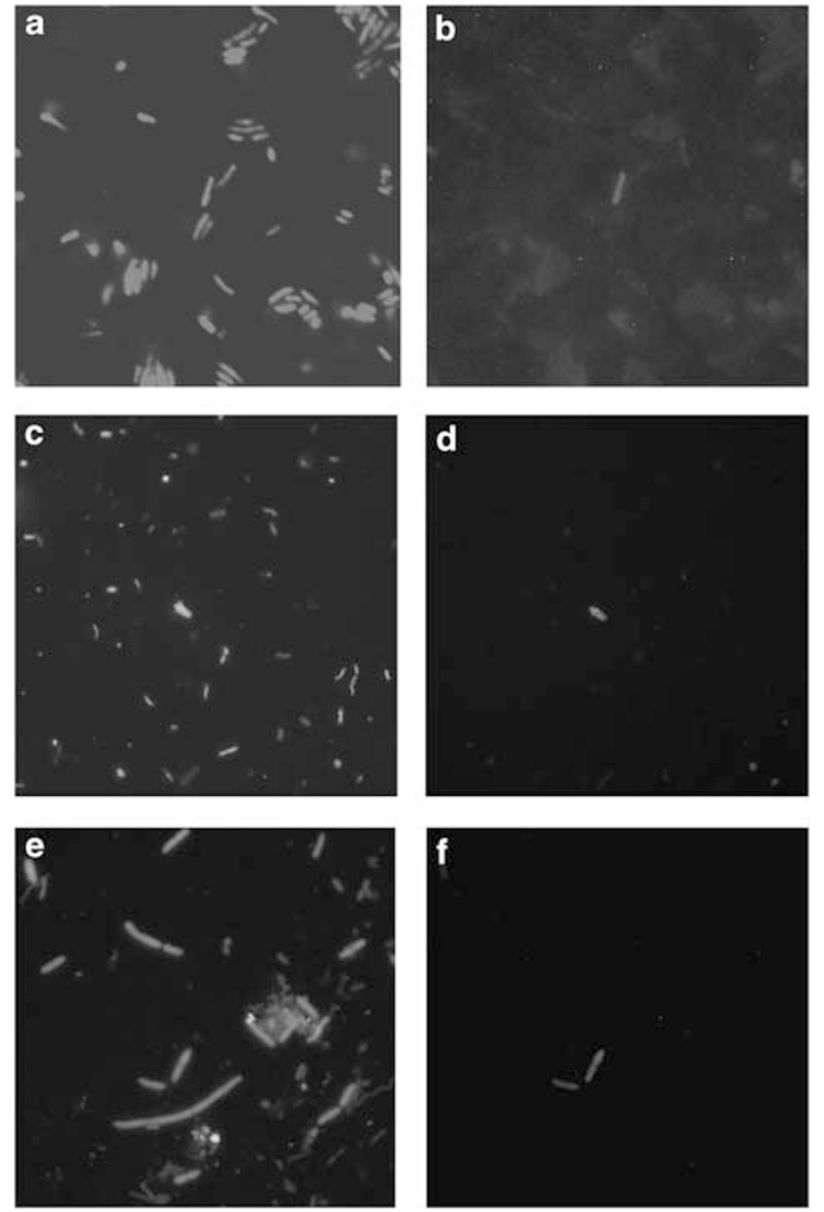

Figure 2 Visualization of viable bacterial cells carrying the specific gene transferred by phage or stained by SYBR Goldlabeled phage. (a and b) Citrobacter freundii cells were mixed with phage P1 $k c$ for $10 \mathrm{~min}$. Viable $C$. freundii cells carrying the bla gene transferred by phage $\mathrm{P} 1 k c$ were detected by a combination of cycling primed in situ amplification-fluorescent in situ hybridization (CPRINS-FISH) and direct viable counting (DVC). (a) 4',6-diamidino-2-phenylindole (DAPI) image. (b) Alexa Fluor 546 image. (c and d) Indigenous bacteria in river water taken at Juhachijo in the Kanzakigawa River were mixed with SYBR Goldlabeled phage EC10 for $20 \mathrm{~min}$. The cells to which phage EC10 injected their DNA were detected by fluorescent bacteriophage assay. (c) DAPI image. (d) SYBR Gold image. (e and f) Indigenous bacteria in river water taken at Juhachijo in the Kanzakigawa River were mixed with phage EC10 for $20 \mathrm{~min}$. Viable indigenous bacterial cells carrying the gfp gene transferred by phage EC10 were detected by a combination of CPRINS-FISH and DVC. (e) DAPI image. (f) Alexa Fluor 546 image. A full-color version of this figure is available at the ISME Journal online.

made it possible to concentrate target cells through filtration, and has advantages in estimating the frequency of gene transfer in samples with low bacterial concentrations, such as natural aquatic environments.

Gene transfer with indigenous bacterial communities as recipients

Potential gene transfer by phages in freshwater environments was examined with bacterial communities from oligotrophic and eutrophic rivers as 
Table 4 Infection range of phage EC10 and DNA transfer frequencies of gfp gene with Enterobacteriaceae strains as recipient ${ }^{\mathrm{a}}$

\begin{tabular}{|c|c|c|c|c|c|}
\hline \multirow[t]{3}{*}{ Recipient } & \multirow[t]{3}{*}{ Plaque $^{\mathrm{b}}$} & \multicolumn{4}{|c|}{ DNA transfer frequency per indicated unit as determined by indicated method } \\
\hline & & \multicolumn{2}{|c|}{ CPRINS $^{\mathrm{c}}$} & \multicolumn{2}{|c|}{ DVC-CPRINS ${ }^{\mathrm{d}}$} \\
\hline & & Per TDC & Per PFU & Per TDC & Per PFU \\
\hline C. freundii & - & $(6 \pm 0.7) \times 10^{-3}$ & $(3 \pm 0.3) \times 10^{-3}$ & $(3 \pm 0.9) \times 10^{-3}$ & $(1 \pm 0.5) \times 10^{-3}$ \\
\hline E. aerogenes & - & $(8 \pm 2) \times 10^{-3}$ & $(4 \pm 0.7) \times 10^{-3}$ & $(3 \pm 0.6) \times 10^{-3}$ & $(1 \pm 0.3) \times 10^{-3}$ \\
\hline P. mirabilis & - & $(5 \pm 1) \times 10^{-3}$ & $(3 \pm 0.6) \times 10^{-3}$ & $(1 \pm 1) \times 10^{-4}$ & $(5 \pm 5) \times 10^{-4}$ \\
\hline S. enteritidis & - & $(7 \pm 0.8) \times 10^{-3}$ & $(3 \pm 4) \times 10^{-3}$ & $(5 \pm 2) \times 10^{-3}$ & $(2 \pm 1) \times 10^{-3}$ \\
\hline S. marcescens & - & $(8 \pm 2) \times 10^{-3}$ & $(4 \pm 1) \times 10^{-3}$ & $(6 \pm 2) \times 10^{-3}$ & $(3 \pm 1) \times 10^{-3}$ \\
\hline
\end{tabular}

Abbreviations: CFU, colony-forming unit; CPRINS-FISH, cycling primed in situ amplification-fluorescent in situ hybridization; DVC, direct viable count; MOI, multiplicity of infection; ND, not detectable; PFU, plaque-forming unit; TDC, total direct count.

${ }^{a}$ Frequencies are shown per TDC or PFU. Values indicate means \pm s.d. values for triplicate samples.

'Infection range was determined by plaque assay. +, positive; -, negative.

${ }^{\mathrm{c}}$ Frequencies were determined by CPRINS-FISH at MOI of 2 .

${ }^{\mathrm{d}}$ Viable cells carrying $g f p$ gene were detected by combined DVC and CPRINS-FISH.

Table 5 DNA transfer frequencies of $g f p$ gene via phage EC10 with different concentration of Escherichia coli NBRC12713 as recipients ${ }^{\mathrm{a}}$

\begin{tabular}{lccr}
\hline Sample & TDC $\left(\right.$ cells ml $\left.{ }^{-1}\right)$ & $\begin{array}{r}\text { DNA transfer frequency } \\
\text { per indicated unit as } \\
\text { determined by CPRINS }\end{array}$ \\
\cline { 2 - 4 } & & Per TDC & Per PFU \\
\hline E. coli & $1.3 \times 10^{8}$ & $(8 \pm 4) \times 10^{-3}$ & $(4 \pm 2) \times 10^{-3}$ \\
E. coli & $1.0 \times 10^{7}$ & $(3 \pm 2) \times 10^{-3}$ & $(2 \pm 0.9) \times 10^{-3}$ \\
E. coli & $1.6 \times 10^{6}$ & $(7 \pm 6) \times 10^{-3}$ & $(4 \pm 3) \times 10^{-3}$ \\
E. coli & $1.6 \times 10^{5}$ & $(3 \pm 2) \times 10^{-3}$ & $(2 \pm 0.8) \times 10^{-3}$ \\
P. putida+E. coli & $3.7 \times 10^{7}$ & $(1 \pm 0.5) \times 10^{-3}$ & $(7 \pm 2) \times 10^{-2}$ \\
P. putida+E. coli & $3.3 \times 10^{6}$ & $(8 \pm 0.7) \times 10^{-4}$ & $(4 \pm 0.3) \times 10^{-2}$ \\
P. putida+E. coli & $4.3 \times 10^{5}$ & $(2 \pm 0.8) \times 10^{-3}$ & $(7 \pm 4) \times 10^{-2}$ \\
\hline
\end{tabular}

Abbreviations: CFU, colony-forming unit; CPRINS-FISH, cycling primed in situ amplification-fluorescent in situ hybridization; DVC, direct viable count; MOI, multiplicity of infection; ND, not detectable; $\mathrm{PFU}$, plaque-forming unit; TDC, total direct count.

${ }^{a}$ Frequencies are shown per TDC or PFU. Values indicate means \pm s.d. values for triplicate samples.

${ }^{\mathrm{b}}$ Frequencies were determined by CPRINS-FISH at MOI of 2 .

${ }^{\mathrm{c}} 1 \%$ of $E$. coli were added to P. putida.

recipients. Four samples were collected from different rivers including the Kanzakigawa River from which phage EC10 was isolated. Plasmid RK2::gfp encodes ampicillin, kanamycin and tetracycline resistance genes (Thomas, 1981), but a significant part of indigenous bacteria from these sites $\left(10^{-5}-10^{-4}\right.$ per TDC) were resistant to these antibiotics. The presence of antibiotic-resistant bacteria in the river samples made it difficult to detect transductants by culture-dependent methods using selective medium. Both E. coli W3110 RK2::gfp and NBRC 12713 RK2::gfp strains were used as donors. There was no difference in the DNA-transfer frequencies between these donor strains when E. coli NBRC 12713 was used as a recipient (data not shown).

To assess the possible range of DNA injection by phage EC10, fluorescent bacteriophage assay was carried out first (Hennes et al., 1995; Noble and
Fuhrman, 2000). Although plaque formation was observed only in E. coli, phage DNA was injected by phage EC10 into $C$. freundii, $E$. aerogenes, $P$. mirabilis, $S$. enteritidis and $S$. marcescens. Fluorescent bacteriophage assay showed that phage EC10 could infect indigenous bacterial cells in river water samples (Figures 2c and d). Only cells stained by fluorescently labeled-phage EC10 emitted the green fluorescence of SYBR Gold under blue excitation (Figure 2d). The frequency of cells stained by SYBR gold-labeled phage EC10 constituted $0.4-2 \times 10^{-2}$ per TDC in the river water samples (Table 6). The abundance of $E$. coli in these rivers determined by FISH with a ribosomal RNA-targeted probe for E. coli (Kenzaka et al., 2001) was about $10^{-4}$ of TDC, which was lower than the numbers determined by fluorescent bacteriophage assay. Thus, phage EC10 was thought to inject DNA into nonE. coli cells in the samples.

The 'mixing ratio' was calculated on the basis of the number of cells stained by SYBR gold-labeled phage EC10 in the river water samples. Then the frequencies of the $g f p$ gene transfers to indigenous bacterial communities were investigated by DVC combined with CPRINS-FISH (Table 6). The DVCpositive cells in river water samples accounted for $15-30 \%$ of the total bacteria at Juhachijo, 9-34\% at Kitahashi, $8-28 \%$ at Kuwazu and $17-24 \%$ at Takiue through the sampling periods. Independent of the mixing ratio $(2,20$ and 200$)$, the DNA-transfer frequencies per TDC determined by CPRINS-FISH or DVC combined with CPRINS-FISH at Juhachijou were similar. Thus, the indigenous bacterial populations to which phage EC10 could inject the $g f p$ gene in river water samples were confined to limited cells.

Gene transfer by phage EC10 was also observed in other river water samples from oligotrophic (Takiue) and eutrophic (Juhachijo, Kitahashi and Kuwazu) sites (Table 6). Indigenous bacteria from these four locations did not show positive signals with CPRINS-FISH before transducing phages were 

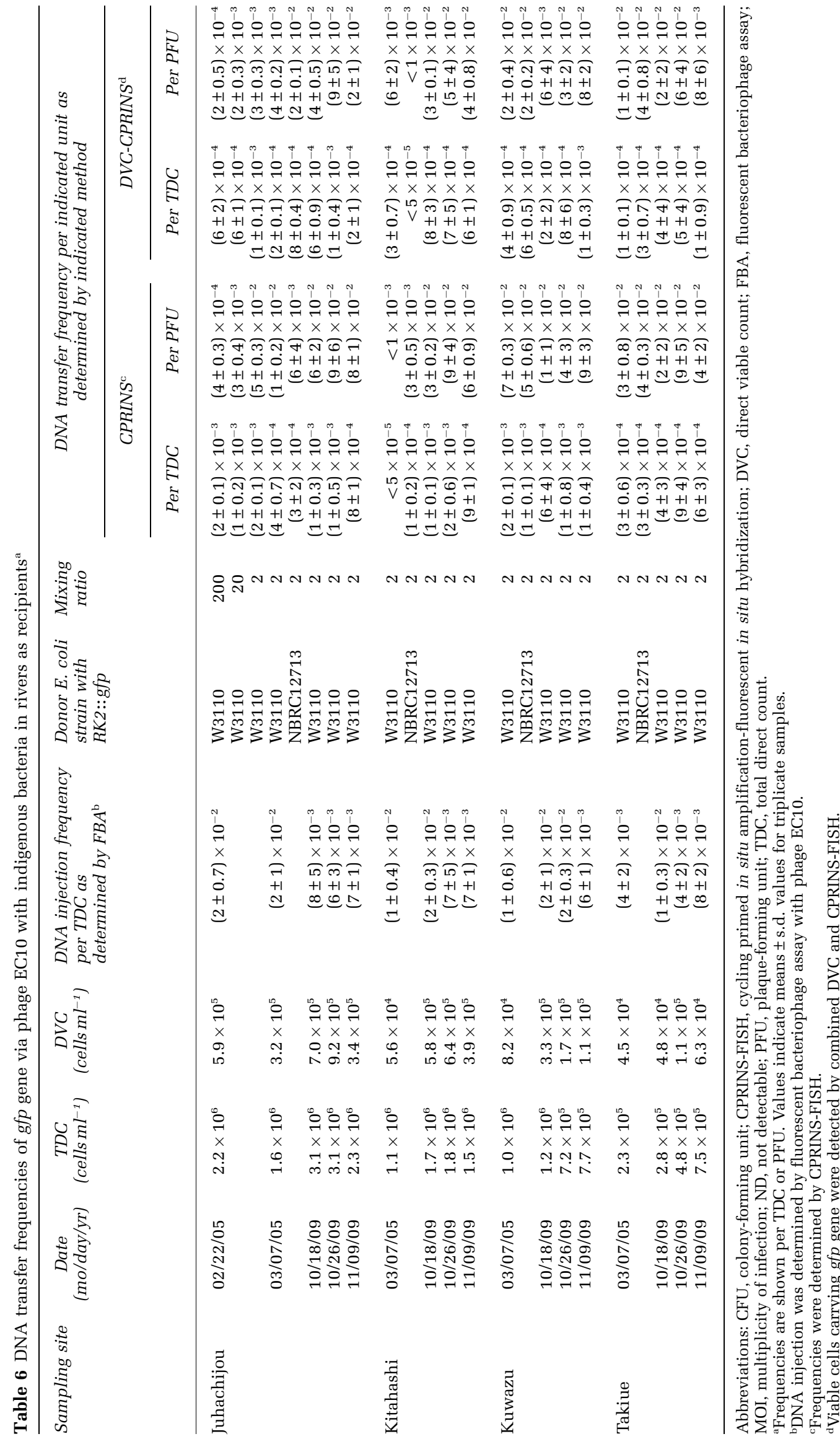
added, but they were CPRINS-FISH positive after gene transfer experiments were performed with phage EC10. The frequencies of $g f p$ gene transfer in these bacterial communities ranged from undetectable to $2 \times 10^{-3}$ cells per TDC, which correspond to undetectable to $9 \times 10^{-2}$ cells per PFU. Viable cells carrying the transferred $g f p$ gene were detected by DVC combined with CPRINS-FISH (Figures 2e and $\mathrm{f}$ ), and they constituted more than $20 \%$ of the gfp gene-positive cells in most cases. The frequencies of $g f p$ gene-positive viable cells ranged from undetectable to $9 \times 10^{-2}$ cells per PFU (undetectable to $1 \times 10^{-3}$ cells per TDC). Although it was hard to detect transductants using the culture-dependent method, DVC combined with CPRINS-FISH clarified the DNA-transfer frequencies through the E. coli phage in the river water samples at the single-cell level. The frequencies of $g f p$ gene-positive viable cells per PFU at each site were compared between early spring and autumn, and among three sampling dates in autumn. Overall, the obtained frequencies at each site were not significantly different among sampling dates $(P>0.05)$ except those at Juhachijo between 7 March 2005 and 18 October $2009(P<0.05)$.

\section{Discussion}

This study attempted to accurately determine the frequency and possible range of DNA transfer mediated by $E$. coli phages using a gene-targeting approach. Although advances in genomics and nucleotide sequence analysis have highlighted the significance of phages in lateral gene transfer as possible contributors to bacterial evolution (Bordenstein and Reznikoff, 2005), transduction frequencies in laboratory experiments using selective media in most studies were generally reported to be low and the range of phage-mediated gene transfer was considered narrow, although broad host-range phages were occasionally found in aquatic environments (Beumer and Robinson, 2005). To understand gene flow among bacteria, sensitive and reliable methods of detecting transferred DNA are necessary, which should have the following properties: (i) recognition of transferred gene in individual cells without the requirement of cultivation or gene expression, (ii) effective concentration of target bacteria that acquire the indicator gene, for example, by filtration, and (iii) identical conditions that can be applied to diverse bacteria because the gene is expected to be transferred to bacteria physiology of which is unclear. In this study, we used a gene-targeting approach based on in situ DNA amplification, which enabled us to determine the frequency and possible range of gene transfer at the single-cell level.

Previous studies show transduction frequencies determined by culture-dependent methods using selective agar media varied over orders of magnitude from $10^{-11}$ to $10^{-5}$ per PFU in freshwater and marine systems (Weinbauer and Rassoulzadegan, 2004). In contrast, DNA-transfer frequencies determined by DVC combined with CPRINS-FISH for $g f p$ gene were up to $3 \times 10^{-3}$ per PFU in Enterobacteriaceae strains, and up to $9 \times 10^{-2}$ per PFU in natural bacterial communities; a few orders of magnitude greater than those previously measured throughout the studied periods.

Conventional methods confirmed that the range of gene transfer by phage P1kc, T4GT7 and EC10 was limited to plaque-forming strains $(E$. coli and E. aerogenes), but CPRINS-FISH revealed that the three E. coli phages could mediate transfer of the gene from E. coli to non-plaque-forming Enterobacteriaceae strains. Specifically, some bacteria, which were not thought to be a 'host' or 'recipient' when conventional methods were used, were able to receive the bacterial gene via the $E$. coli phages. The phage life cycle consists of adsorption into a cell, injection of nucleic acid, commandeering of host machinery, production of phage proteins and nucleic acid, assembly and release by either lysis or extrusion (Wommack and Colwell, 2000). For visible plaques, it is necessary to complete these processes and disperse effectively within soft agar. Certain phages in natural environments do not form plaques on any known host because they have the mechanism to suppress host lysis (lysogeny), have a mutation in the genes responsible for lysis or lack genetic material themselves (defective phage; Garro and Marmur, 1970). The presence of such phages masks actual host range. The gene-targeting approach described here makes it possible to detect target DNA sequences in bacterial cells without cultivation or gene expression, and is less likely to be biased by physiological or genetic (that is, marker expression) limitations. Consequently, our results suggest that DNA exchange among bacteria via phage may occur in a more divergent range of bacteria than previously thought using conventional methods.

The entry of DNA into a recipient bacterium is an important first step in genetic diversification through lateral gene transfer. On DNA entry into a cell, binding between the phage receptor on the cell surface and the tail fiber on the phage is necessary. Our results show that three E. Coli phages (P1kc, T4GT7 and EC10) attached on more divergent strains than those estimated by conventional methods, and transferred the E. coli gene to the strains (Table 1, 2, and 4). These results indicate that the binding between the phage receptor and the tail fiber might be more plastic than previously thought. In addition, the structure of the phage receptor on the cell surface and the tail fiber on the phage could be changed by mutation (Yu and Mizushima, 1982; Tetart et al., 1996). This would allow the movement of DNA molecules among more divergent genera mediated by phages more frequently.

The fate of the transferred gene in recipient cells is of interest for genomic diversity studies. During the incubation for DVC, a proportion of transferred genes inside recipient cells may be destroyed, 
but DVC combined with CPRINS-FISH showed that a significant proportion of the transferred gene remained in viable recipient cells. Potential future study should examine the frequency and mechanism of the maintenance of transferred genes and aim to elucidate the mechanism of maintenance based on DNA sequence.

Previous studies have shown that a high degree of genomic diversity may occur among closely related genomes (Ohnishi et al., 2002). Genomes of Vibrio splendidus in natural coastal areas showed extensive allelic diversity, and the group consists of at least 1000 distinct genotypes in $1 \mathrm{ml}$ of sea water (Thompson et al., 2005). Such variation might arise because of DNA exchange among microorganisms at the single-cell level. Several prokaryotic genomes contain large fractions of foreign genes, for example, more than $15 \%$ of the genes of $E$. coli have been acquired by lateral gene transfer (Lawrence and Ochman, 1998). The events of gene transfer have significantly driven diversification in the bacterial genome.

This study offers a way to address the movement of a specific gene among bacterial cells in situ, regardless of culturability or gene expression. Our results suggest that DNA exchange among bacteria via phages in natural aquatic environments may occur in a more divergent range of bacteria and more frequently than thought previously using conventional methods. 'Lateral gene transfer', in the general meaning, consists of several steps: entry of the foreign gene into viable recipient cells, gene replication, maintenance during cell growth, gene expression and so forth. Reporter gene technology, such as green fluorescent protein, allows the estimation of bacterial cells in which the reporter gene is expressed (Dahlberg et al., 1998; Hendrickx et al., 2003), although potential limitations and advantages have been discussed (Sorensen et al., 2005; Maruyama et al., 2006). Our approach has a great potential to provide more quantitative information on gene transfer steps in the natural environment. It will be important in the future to clarify whether such extensive gene transfer events via phages observed at the single-cell level are a general feature of interactions between natural bacteria and phages using other phage-host systems.

\section{Acknowledgements}

This study was supported by the JSPS Grant-in-Aid for Young Scientists (B) (18780055).

\section{References}

Altschul SF, Madden TL, Schaffer AA, Zhang J, Zhang Z, Miller W et al. (1997). Gapped BLAST and PSI-BLAST: a new generation of protein database search programs. Nucleic Acids Res 25: 3389-3402.
Amann RI, Ludwig W, Schleifer KH. (1995). Phylogenetic identification and in situ detection of individual microbial cells without cultivation. Microbiol Rev 59: 143-169.

Beumer A, Robinson JB. (2005). A broad-host-range, generalized transducing phage (SN-T) acquires 16S rRNA genes from different genera of bacteria. Appl Environ Microbiol 71: 8301-8304.

Bordenstein SR, Reznikoff WS. (2005). Mobile DNA in obligate intracellular bacteria. Nature Rev Microbiol 3: 688-699.

Brüssow H, Canchaya C, Hardt WD. (2004). Phages and the evolution of bacterial pathogens: from genomic rearrangements to lysogenic conversion. Microbiol Mol Biol Rev 68: 560-602.

Dahlberg C, Bergstrom M, Hermansson M. (1998). In situ detection of high levels of horizontal plasmid transfer in marine bacterial communities. Appl Environ Microbiol 64: 2670-2675.

Enomoto M, Stocker BA. (1974). Transduction by phage P1kc in Salmonella typhimurium. Virology 60: 503-514.

Fuhrman JA. (1999). Marine viruses and their biogeochemical and ecological effects. Nature 399: 541-548.

Garro AJ, Marmur J. (1970). Defective bacteriophages. J Cell Physiol 76: 253-263.

Goldberg RB, Bender RA, Streicher SL. (1974). Direct selection for P1-sensitive mutants of enteric bacteria. J Bacteriol 118: 810-814.

Hendrickx L, Hausner M, Wuertz S. (2003). Natural genetic transformation in monoculture Acinetobacter sp. strain BD413 biofilms. Appl Environ Microbiol 69: 1721-1727.

Hennes KP, Suttle CA, Chan AM. (1995). Fluorescently labeled virus probes show that natural virus populations can control the structure of marine microbial communities. Appl Environ Microbiol 61: 3623-3627.

Jiang SC, Paul JH. (1998). Gene transfer by transduction in the marine environment. Appl Environ Microbiol 64: 2780-2787.

Jorquera M, Yamaguchi N, Tani K, Nasu M. (2006). A combination of direct viable counting, fluorescence in situ hybridization, and green fluorescent protein gene expression for estimating plasmid transfer at the single cell level. Microbes Environ 21: 101-111.

Joux F, Lebaron P. (1997). Ecological implications of an improved direct viable count method for aquatic bacteria. Appl Environ Microbiol 63: 3643-3647.

Kenzaka T, Tamaki S, Yamaguchi N, Tani K, Nasu M. (2005). Recognition of individual genes in diverse microorganisms by cycling primed in situ amplification. Appl Environ Microbiol 71: 7236-7244.

Kenzaka T, Tani K, Sakotani A, Yamaguchi N, Nasu M. (2007). High frequency phage-mediated gene transfer among Escherichia coli determined at the single cell level. Appl Environ Microbiol 73: 3291-3299.

Kenzaka T, Yamaguchi N, Prapagdee B, Mikami E, Nasu M. (2001). Bacterial community composition and activity in urban rivers in Thailand and Malaysia. J Health Sci 47: 353-361.

Kenzaka T, Yamaguchi N, Tani K, Nasu M. (1998). rRNAtargeted fluorescent in situ hybridization analysis of bacterial community structure in river water. Microbiology 144: 2085-2093.

Kogure K, Simidu U, Taga N. (1979). A tentative direct microscopic method for counting living marine bacteria. Can J Microbiol 25: 415-420.

Lawrence JG, Ochman H. (1998). Molecular archaeology of the Escherichia coli genome. Proc Natl Acad Sci USA 95: 9413-9417. 
Maniatis T, Fritsch EF, Sambrook J. (1982). Molecular Cloning. A laboratory manual. Isolation of bacteriophage Lambda and plasmid DNA. pp 75-85.

Maruyama F, Kenzaka T, Yamaguchi N, Tani K, Nasu M. (2005). Visualization and enumeration of bacteria carrying a specific gene sequence by in situ rolling circle amplification. Appl Environ Microbiol 71: 7933-7940.

Maruyama F, Tani K, Kenzaka T, Yamaguchi N, Nasu M. (2006). Quantitative determination of free-DNA uptake in river bacteria at the single-cell level by in situ rolling-circle amplification. Appl Environ Microbiol 72: 6248-6256.

Noble RT, Fuhrman JA. (2000). Rapid virus production and removal as measured with fluorescently labeled viruses as tracers. Appl Environ Microbiol 66: 3790-3797.

Ochman H, Lawrence JG, Groisman EA. (2000). Lateral gene transfer and the nature of bacterial innovation. Nature 405: 299-304.

Ogunseitan OA. (2008). Genetic transduction in freshwater ecosystems. Freshwater Biol 53: 1228-1239.

Ohnishi M, Terajima J, Kurokawa K, Nakayama K, Murata T, Tamura K et al. (2002). Genomic diversity of enterohemorrhagic Escherichia coli 0157 revealed by whole genome PCR scanning. Proc Natl Acad Sci USA 99: 17043-17048.

Pallen MJ, Wren BW. (2007). Bacterial pathogenomics. Nature 449: 835-842.

Saye DJ, Ogunseitan O, Sayler GS, Miller RV. (1987). Potential for transduction of plasmids in a natural freshwater environment: effect of plasmid donor concentration and a natural microbial community on transduction in Pseudomonas aeruginosa. Appl Environ Microbiol 53: 987-995.

Sorensen SJ, Bailey M, Hansen LH, Kroer N, Wuertz S. (2005). Studying plasmid horizontal transfer in situ: a critical review. Nature Rev Microbiol 3: 700-710.
Tani K, Chen JM, Yamaguchi N, Nasu M. (1996). Estimation of bacterial volume and biomass by scanning electron microscopic image analysis. Microbes Environ 11: $11-17$.

Tetart F, Repoila F, Monod C, Krisch HM. (1996). Bacteriophage T4 host range is expanded by duplications of a small domain of the tail fiber adhesion. $J \mathrm{Mol}$ Biol 258: 726-731.

Teuber M. (2001). Veterinary use and antibiotic resistance. Curr Opin Microbiol 4: 493-499.

Thomas CM. (1981). Molecular genetics of broad host range plasmid RK2. Plasmid 5: 10-19.

Thompson JR, Pacocha S, Pharino C, Klepac-Ceraj V, Hunt DE, Benoit J et al. (2005). Genotypic diversity within a natural coastal bacterioplankton population. Science 307: 1311-1313.

Weinbauer MG, Rassoulzadegan F. (2004). Are viruses driving microbial diversification and diversity? Environ Microbiol 6: 1-11.

Wilson GG, Young KY, Edlin GJ, Konigsberg W. (1979). High-frequency generalised transduction by bacteriophage T4. Nature 280: $80-82$.

Wommack KE, Colwell RR. (2000). Virioplankton: viruses in aquatic ecosystems. Microbiol Mol Biol Rev 64: 69-114.

Yamaguchi N, Nasu M. (1997). Flow cytometric analysis of bacterial respiratory enzymatic activity in the natural aquatic environment. J Appl Microbiol 83: 43-52.

Yu F, Mizushima S. (1982). Roles of lipopolysaccharide and outer membrane protein OmpC of Escherichia coli $\mathrm{K}-12$ in the receptor function for bacteriophage T4. $J$ Bacteriol 151: 718-722.

Zeph LR, Onaga MA, Stotzky G. (1988). Transduction of Escherichia coli by bacteriophage P1 in soil. Appl Environ Microbiol 54: 1731-1737.

Zinder ND, Lederberg J. (1952). Genetic exchange in Salmonella. J Bacteriol 64: 679-699. 